\title{
The Artistic Characteristics of Huaxian's Shadow Play Music and the Xifu Regional Culture Inheritance
}

\author{
Qian Wang ${ }^{1, a}$ \\ ${ }^{1}$ Xianyang Normal University, Shaanxi, Xianyang, China, 712000
}

\begin{abstract}
Keywords: Artistic Characteristics, Shadow Play Music, Wanwan Accent, Xifu Regional Culture Inheritance
\end{abstract}

\begin{abstract}
With the development of social and cultural system, the protection of intangible cultural heritage and the inheritance of regional excellent culture have become the main content of cultural development. Shadow play has been widely regarded as the carrier of Chinese shadow art culture. Among them, Huaxian shadow occupies an important position in the development history of the shadow play at home and abroad, and its representative music art features inherit the oldest and most traditional music attributes, which is of great significance to the cultural inheritance of the whole Xi Fu government area. This paper analyzes the musical art attributes of Huaxian shadow play, and analyzes the relationship between the cultural heritage and the cultural heritage of the $\mathrm{Xi}$ Fu government.
\end{abstract}

\section{Introduction}

Huaxian shadow play, early 80s, has also become a time shadow play, the late 80s, also known as Wan wan cavity shadow play. In the early Qing Dynasty, the Qing Emperor Qianlong, the Jiaqing period, the dramatist Li Fanggui and other literati, gave birth to a bowl, and a lot of traditional repertoire, such as the "Top Ten", was called the " China and the world's oldest folk art of the Han nationality, is the Han folk arts and crafts and opera clever combination. And the development of Huaxian shadow play has been recognized by the community, starting from the founding of new China, Huaxian shadow play out of the county, in Xi'an, 1975, Huaxian shadow shadow to Beijing won the praise. 1936 on the Huaxian shadow play the documentary "Shadow Qingqi" comes out. In the 21st century, with the construction of traditional cultural system, Huaxian shadow play as outstanding folk culture and art, in 2005 the county won the Shaanxi Province folk art shadow town, "the title, in 2006 by the Ministry of Culture included in the" first batch of non-material Cultural heritage protection list ", in 2007 was included in the" first batch of non-material cultural heritage protection list ", 2008 Huaxian shadow industry group by the National Ministry of Culture named the national cultural industry demonstration base, Huaxian due to shadow by the national culture Ministry of naming the country folk culture and art town.

\section{The Art Features of Huaxian Shadow Music}

The Singing Characteristics. Huaxian shadow play the main form is singing to the main, the overall form of music is "Wan Wan" reflected, Wan Wan produced in the Tang Dynasty, the overall embodiment of the delicate and pleasant, lingering pretty features, its absorption The art of the old cavity in the performance of the entire shadow play in the process, not only unique, melodious, elegant music, and there are lyrical, beautiful, touching singing, this singing form in many shadow play in a unique style. Bowl can be melodious and delicate features, to control a variety of repertoire, colleagues through the euphemism singing the grand scene to express it. In the "sell goods Lang", the sellers side of the side of the smoke and Miss rich bargain, both vivid and humorous, female singing graceful and moving. In the bowl of the cavity of the music form, the joy and sadness of the two scenarios were used to "cheer" and "bad sound" reflected, the whole singing process, read the word part of the use of real sound, help cavity with fake, The actual use of the actual situation, in addition to the use of Adagio, fast three, slow tight board, Yang sentence, such as plate road, so that the entire film performance rich sense of hierarchy. For example, "knife split 
Han-day", the Di Qing, Han Tianhua two generals chase between the chop, accompanied by a quick beat of the instrument, it is thrilling, some fighting, caught off guard, Han Tianhua was Diqing cut in the moment, the story of this clean end. We can see the art of bowls bowl of art is amazing, after listening to people soul-stirring.

Different situations using different tone, and because the Huaxian shadow play is mainly used seven words on the next, the next paragraph of the phrase, usually at the end of the use of the fourth tone, just urging the end of neat, and only sing a sentence, Melody down the sound, people have the meaning of the meaning of the rhyme still have the feeling. In addition, different repertoire clauses and different paragraphs, in order to ensure that the emotional consistency of singing, usually in a singing idea, to ensure that the level of ups and downs, such as in cheerful, clear mood, singing style ups and downs Large, and tone to keep the treble, the performance of sadness, sad mood, the overall tone is low. For example, in the "white fine" in the life of Li Qingyan to Zhenjiang Miss Shang Fei Qiong, the two love at first sight, Fei Qiong left white jade Tian Li gift, Li Zijin goldfish fly Fei, love each other, the dream of love in the paragraph, the whole tone to maintain a higher, showing a happy situation. Adjust the tone of the four tones to express the lyrics of the thoughts and feelings, and according to the length of the lyrics, and the beat of the scattered, from the tone or up tone, into the situation, and then the end of the tune to ensure the end of the shadow play decisive.

The Singing Characteristics. The original song of the original version of the song for the sound music, after the film in the play in the county in order to cooperate with the performance, then changed with the instrumental music, and therefore in the shadow of the music art performance, but also reflected in the instrumental music. Huaxian shadow play the artistic characteristics of the song as "clean and mixed, with considerable feelings." The so-called clear and mixed, refers to the clear brand and brand, clear brand is mainly reflected in the help of the cavity, the mix of brands minus the percussion, only by the suona playing tunes, and mixed brand reflected in the singing, the big sign to remove the lyrics, only by the suona playing tunes, and add percussion accompaniment, used to reflect the situation. In these two music cards, in order to ensure the accuracy of emotional transmission, but also with a different tune, used to match the song singing, and even each repertoire has a separate style, style and tone. In addition, different tunes are mainly used with different board road to use, the use of the board, slow board, tight board and 26 board, fan board reflects the tension of singing, the use of 28 board, Yang sentence, Three missing, single sentence sent to reflect the changes in the situation to "Golden Beach" began to select the section, for example, in the beginning, free long sound of free challenge into the situation, and then began to improve the tune, the use of slow plate, And then use the tight plate leads to the theme of singing. In general, in the tune, the request to speak on the light round, tenderness like water helps on the disease $\mathrm{Xu}$ thin.

The Features of Musical Instrument. The art features of the instrument are mainly embodied in the "many and not mixed, and the other", the use of musical instruments, including the piano, chord, kins, drums, relative to the simple form of shadow play in terms of its use of musical instruments The number is more, but because the shadow play is mainly by the people with, in general, the shadow play can be chapter orderly, not messy. In addition to the different scenes of the embodiment of the Huaxian shadow play the instrument is generally used to maintain a variety of musical instruments at the same time to use the vocal music to create a scene, but in this vocal fusion of the use of the case, but also to grasp the different instruments Use the tone and the use of time, thus ensuring the instrument level differences. For example, in the "golden bowl hairpin" by the repertoire, describes the sixteen-year-old Taolin Bi Yuhua small spring when playing, singing the name of "surname Taozhuang live peach village, hut grass in the peach standard. "The four sentences, the use of two strings of 63 sounds and the board of the 52 sound, the piano of the 51 sound of the tune, the tone of the instrument blend, but it can reflect the characteristics of a variety of musical instruments and enrich the contents of the whole singing, to express the scene of the three-dimensional show.

There are three kinds of musical instruments in the Huaxian shadow play. The artistic features of the three instruments are mainly composed of: drums, through the percussion, drums and control of 
the percussion force, you can get a large volume and sound Contrast, but also to play a complex point of consumption, the mood and the atmosphere of the rendering has a greater role, a large gong are metal body Ming musical instruments, no fixed pitch. Cymbals of the basic playing method are forced to hit, but also through the subtle way to play a different sound to the sound. Often, gongs are used to express a tense atmosphere and ominous omen, with a very unique artistic effect. It can be hit, get loud like a hurricane or lightning effect, you can also flick or two hammer tune, reminiscent of the sound of water. In addition, there are obvious regional art attributes of the piano, $\mathrm{Hu}$ board, suona, side drums, speakers, these instruments are mainly based on the West House area of custom and music attributes to improve, applied to the shadow play, used to reflect the situation in the region.

\section{The Art Characteristics of Huaxian Shadow Music and Xifu Cultural Heritage}

The Relationship between the Huaxian Shadow Music and Xifu Cultural Heritage. Huaxian shadow is the traditional voyage of the West House heritage. Huaxian shadow is a branch of "Chinese opera", its historical development, based on the Tang Dynasty prevailing singing on the root, coupled with the West House local opera and local dialect under the dual role of the formation of today's independent singing, the traditional singing of the West House was carried out in two aspects. On the one hand, the singing of the opera in Hua County was originally set in the Tang Dynasty pear and the sound of the music in the local theater. And the development so far, the formation of a unique bowl of the bowl, but in contrast with other Shaanxi shadow opera singing, bowl bowl of historical inheritance strong, its traditional voyage of the west of the most obvious inheritance, retain a large part of the traditional singing. On the other hand, due to the shadow play on the new tone and the ability to absorb the music body, in the development process, based on the pattern of singing, the formation of a change in the sound of the West Village area of the film and the song of the absorption and development to a certain extent, it is the traditional development of the Xi Fu House singing.

Huaxian shadow is the embodiment of the cultural heritage of the West House film. For the development of the film, according to historical records, that the origin of Chinese film in Shaanxi, Shaanxi and Shaanxi film originated in Huaxian, therefore can be drawn in Huaxian film drama cultural heritage embodies the development of the West House film culture. A part of the musical form of the Yihua County Shadow Play is derived from the film of the West House, which draws on the musical form of the film in the West House, including the music singing and the tone of the film in the cavity. Therefore, the development of the musical form the development of the culture of the $\mathrm{Xi} \mathrm{Fu} \mathrm{government} \mathrm{film} \mathrm{culture;} \mathrm{its} \mathrm{two} \mathrm{Huaxian} \mathrm{shadow} \mathrm{is} \mathrm{the} \mathrm{West} \mathrm{Village} \mathrm{film} \mathrm{culture} \mathrm{branch,} \mathrm{due}$ to the West House regional folk culture marketing, making Huaxian shadow shadow on the other areas of the West film area of the opera combination and absorption.

Ensure the Huaxian Shadow Play Heritage to Promote the Xifu Cultural Heritage. As Huaxian shadow inheritance is part of the cultural heritage of the West, to ensure that Huaxian shadow heritage, to promote the development of the West cultural heritage system, should not spare no effort to ensure that Huaxian shadow shadow heritage. One of the construction of Huaxian shadow shadow cultural heritage system. We will further increase the inheritance of the shadow culture of Huaxian County, increase capital investment and policy support, and promote the absorption and integration of modern art features of modern music and performances in Huaxian Paper Shadow, and ensure the times of Huaxian shadow play West cultural heritage. Second, the expansion of Huaxian shadow play platform. To create a video platform as the main cultural carrier of the exchange between the film platform, the use of the exchange platform will be scattered shadow culture to gather and meet, produce a complete culture at the same time to expand the influence of Huaxian shadow culture, that is, through the convergence of scattered shadow culture to increase the scale of the entire West culture, so as to protect the development of culture. 


\section{Conclusion}

Huaxian shadow as one of the representatives of the outstanding folk traditional culture, it is of great significance to the inheritance of traditional culture in China, and embodies the inheritance and fit of the musical characteristics of the shadow play in the process of the evolution of the shadow play in Huaxian County. In the process, it retains the traditional music characteristics, but also with the times, it absorbs and integrates the characteristics of different stages of music, it will be transformed into their own attributes. From the perspective of music development, it not only reflects the integration of their singing and music development, but also reflects the inclusive of outstanding culture in the heritage process of Xi Fu culture.

\section{References}

[1] Dai Zhuo Ya, Bai Jingjing, Guo Mianqing, Rong Yan, Liang Anhe. Analysis of the intangible cultural heritage protection and inheritance - Taking Shaanxi Huaxian shadow play as an example[J]. New Silk Road (late), 2016:116 - 122

[2] Yang Xue. A Comparative Study on the Musical Characteristics of the Shadow and Shadow Art in Huaxian County [J]; Journal of Shaanxi Normal University (Philosophy and Social Sciences Edition)

[3] Zhang Yanhua. Huaxian shadow shadow of the aesthetic art and inheritance [D]. Shaanxi Normal University, 2014

[4] Zhang Fan. Huaxian shadow play folk culture research [D]. Qinghai Normal University, 2012

[5] Han Yu. Huaxian shadow study [D]. Central University for Nationalities, 2011

[6] Zhang Yue Sheng. Shaanxi Huaxian folk shadow play[J]. Township Forum, 2005, (14): 50.

[7] Huang Xue. Huaxian shadow shadow of the artistic spirit [D]. Xi'an Academy of Fine Arts, 2005

[8] Lv Ziqiang. Bowl of the moon [J]. Musical instruments, 1984, (04): 24. 